\title{
A plate reader-based method for cell water permeability measurement
}

R. A. Fenton, H. B. Moeller, S. Nielsen, B. L. de Groot and M. Rützler

Am J Physiol Renal Physiol 298:F224-F230, 2010. First published 4 November 2009; doi:10.1152/ajprenal.00463.2009

You might find this additional info useful...

This article cites 37 articles, 23 of which can be accessed free at:

http://ajprenal.physiology.org/content/298/1/F224.full.html\#ref-list-1

This article has been cited by 1 other HighWire hosted articles

Aquaporin-9 Protein Is the Primary Route of Hepatocyte Glycerol Uptake for Glycerol Gluconeogenesis in Mice

Sabina Jelen, Sören Wacker, Camilo Aponte-Santamaría, Martin Skott, Aleksandra Rojek,

Urban Johanson, Per Kjellbom, Søren Nielsen, Bert L. de Groot and Michael Rützler

J. Biol. Chem., December 30, 2011; 286 (52): 44319-44325.

[Abstract] [Full Text] [PDF]

Updated information and services including high resolution figures, can be found at:

http://ajprenal.physiology.org/content/298/1/F224.full.html

Additional material and information about AJP - Renal Physiology can be found at: http://www.the-aps.org/publications/ajprenal

This information is current as of June 5, 2012.

AJP - Renal Physiology publishes original manuscripts on a broad range of subjects relating to the kidney, urinary tract, and their respective cells and vasculature, as well as to the control of body fluid volume and composition. It is published 12 times a year (monthly) by the American Physiological Society, 9650 Rockville Pike, Bethesda MD 20814-3991. Copyright @ 2010 by the

American Physiological Society. ISSN: 1931-857X, ESSN: 1522-1466. Visit our website at http://www.the-aps.org/. 


\title{
A plate reader-based method for cell water permeability measurement
}

\author{
R. A. Fenton, ${ }^{1}$ H. B. Moeller, ${ }^{1}$ S. Nielsen, ${ }^{1}$ B. L. de Groot, ${ }^{2}$ and M. Rützler ${ }^{1}$ \\ ${ }^{1}$ The Water and Salt Research Center, Institute of Anatomy, University of Aarhus, Aarhus C, Denmark; and ${ }^{2}$ Department \\ of Theoretical and Computational Biophysics, Computational Biomolecular Dynamics Group, Max-Planck-Institute \\ for Biophysical Chemistry, Göttingen, Germany
}

Submitted 11 August 2009; accepted in final form 30 October 2009

Fenton RA, Moeller HB, Nielsen S, de Groot BL, Rützler M. A plate reader-based method for cell water permeability measurement. Am J Physiol Renal Physiol 298: F224-F230, 2010. First published November 4, 2009; doi:10.1152/ajprenal.00463.2009.-Cell volume and water permeability measurements in cultured mammalian cells are typically conducted under a light microscope. Many of the employed approaches are time consuming and not applicable to a study of confluent epithelial cell monolayers. We present here an adaptation of a calcein-quenching-based approach for a plate reader. A standard curve of fluorescence intensities at equilibrium has been recorded, following a shift from $285 \mathrm{mosmol} / \mathrm{kgH}_{2} \mathrm{O}$ to a series of altered extracellular osmolyte concentrations, ranging from final concentrations of 185 to $585 \mathrm{mosmol} / \mathrm{kgH}_{2} \mathrm{O}$, by changing buffer Dmannitol concentrations. Similarly, according average cell volumes have been measured in suspension in a Coulter counter (particlesizing device). Based on these measurements, we have derived an equation that facilitates the modeling of cell volume changes based on fluorescence intensity changes. We have utilized the method to study the role of a carboxyl-terminus aquaporin (AQP)-2 phosphorylation site, which is known to affect AQP2 membrane trafficking, in heterologous type I Madin-Darby canine kidney cells. We find that water permeability in cells expressing phosphorylation site mutants was in the following order: AQP2-S256D > AQP2 wild-type > AQP2S256A. We propose that the method can be applied to study AQP function and more generally to study cell volume changes in adherent cell lines. Furthermore, it should be adaptable for AQP inhibitor screening in chemical compound libraries.

aquaporin-2; calcein, Madin-Darby canine kidney cells

WATER HOMEOSTASIS IN HIGHER organisms requires precise regulation of water and solute reabsorption and excretion by the kidney. To date, numerous transporters and channels necessary for these processes have been characterized (7). These include several aquaporin (AQP) water channels, expressed in the proximal tubule and thin descending limb (AQP1) and the principal cells of the collecting duct (AQP2, -3, and -4), as well as the facilitative urea transporters expressed in the inner medullary collecting duct (UT-A1/3), descending thin limb of Henle's loop (UT-A2), and descending vasa recta (UT-B) (8). Water flux through AQPs is typically measured as the rate of volume change in cells or vesicles following osmotic challenge with a nonpermeable solute. Several experimental setups have been utilized to date (for a comprehensive review, see Ref. 35).

AQP channel function can be studied in proteoliposomes utilizing the stopped-flow, light-scattering technique (37), where vesicles are exposed to a rapid change in buffer osmolality and scattered light intensity is recorded to monitor vesicle volume change. Similarly, vesicles may be loaded with high

Address for reprint requests and other correspondence: M. Rützler, Institute of Anatomy, Aarhus Univ., Wilhelm Meyers Allè, Bldg. 1233, DK-8000 Aarhus C, Denmark (e-mail: mrr@ana.au.dk). concentrations of a fluorescent dye. Upon a decrease in vesicle volume, dye self-quenching occurs by a process that is not very well understood but may depend on dye dimerization, energy transfer to nonfluorescent dimers, and collisional quenching interactions between dye monomers (2). Analysis of AQP channel function can also be conducted in Xenopus laevis oocytes, where heterologous AQP protein expression is achieved through cytoplasmic injection of in vitro transcribed RNA, and oocyte volume changes are recorded under a microscope attached to a video camera. The initial characterization of AQP water channel function was performed in this way (25). More recently, X. laevis oocytes have been utilized to examine the role of phosphorylation in mediating AQP-2 function (20). Importantly, one limitation of these studies (and all studies in $X$. laevis oocytes) was that the trafficking behavior of AQP2 had to be studied at $<20^{\circ} \mathrm{C}$. At this temperature, mutations that alter trafficking at higher temperature (i.e., $37^{\circ} \mathrm{C}$ ) might not affect AQP2 plasma membrane insertion. Furthermore, necessary accessory proteins for proper AQP2 trafficking in principal cells of the kidney collecting duct may not be present in these cells from an ectothermic species.

A number of experimental setups to study AQP function in mammalian cells have also been described (4), but the majority of these techniques are not suited for the study of AQP function in epithelial cell sheets. However, Hamann et al. (12) found that in living cells microinjected with calcein, total fluorescence intensity rapidly rose to a maximum, before steadily declining upon further increases in intracellular calcein concentrations, indicating concentration- and consequently cell volume-dependent fluorescence quenching. This suggests that the technique could be suitable for investigation of AQP function in epithelial cell sheets, but application of the technique under a fluorescent microscope is time consuming.

In this manuscript, we describe adaption of this calceinquenching-based method for cell water permeability measurements using a plate reader and have tested three well-described AQP2 phosphorylation mutants to validate the applicability of our plate reader-based method. This method can expedite cell water permeability measurements, compared with measurements under a fluorescent microscope. A strategy for measuring average cell water permeability coefficients $\left(P_{\mathrm{f}}\right)$ from Madin-Darby canine kidney (MDCK) type I cells is outlined and potential caveats are discussed. Based on our current experience, the outlined strategy should be applicable to measure cell volume changes and cell water permeability from a variety of adherent cell types.

\section{MATERIALS AND METHODS}

Stable cell lines and cell culture. Mutations mimicking constitutively phosphorylated and nonphosphorylated forms of mouse AQP2 at amino acid position 256 were generated by standard site-directed 
mutagenesis (Stratagene). Generation of stable AQP2-expressing cell lines was as described previously (13). Stably transfected cells were grown in DMEM+GlutaMAX (+4.5 g/l D-glucose, + pyruvate) supplemented with $10 \%$ donor bovine serum, penicillin $\mathrm{G}$ sodium $(100$ $\mathrm{U} / \mathrm{ml})$, streptomycin sulfate $(100 \mu \mathrm{g} / \mathrm{ml})$, and hygromycin $(250 \mu \mathrm{g} /$ $\mathrm{ml}$; all media components were purchased from Invitrogen). All lines were grown at $37^{\circ} \mathrm{C}$ and $5 \% \mathrm{CO}_{2}$.

Fluorescence-quenching assays. MDCK cells were seeded on black, clear bottom plates (Corning) and grown for 2 days at $37^{\circ} \mathrm{C}, 5 \%$ $\mathrm{CO}_{2}, 95 \%$ relative humidity in DMEM supplemented with donor bovine serum. Before loading the cells with calcein-AM ester (BD Biosciences) in assay buffer $\left(0.8 \mathrm{mM} \mathrm{MgSO}_{4} ; 5 \mathrm{mM} \mathrm{KCl} ; 1.8 \mathrm{mM}\right.$ $\mathrm{CaCl} ; 25 \mathrm{mM}$ Na-HEPES, pH 7.4, with $\mathrm{HCl} ; 188$ mM D-mannitol; 5 $\mathrm{mM}$ probenecid), the growth medium was exchanged with fresh medium for $1 \mathrm{~h}$. All assay plates were washed with fresh assay buffer containing $0.1 \%$ DMSO three times before incubation in assay buffer $+0.1 \%$ DMSO. Osmotic values recorded on a freeze depression osmometer for assay buffer ranged between 280 and 300 mosmol $/ \mathrm{kgH}_{2} \mathrm{O}$. Calcein fluorescence was recorded on a Fluostar Optima plate reader (BMG Labtech) equipped with a 495-nm bandpass filter for excitation and a 520-nm long-pass filter for emission. Osmotic gradients were applied $5 \mathrm{~s}$ after the beginning of each reading through the instrument's liquid-handling system by addition of assay buffer containing $0.1 \%$ DMSO and altered D-mannitol concentrations, while the concentration of all other extracellular solutes was kept identical. It has been demonstrated previously that in this way osmotic gradients can be applied without affecting membrane potential (19). Recording of fluorescence signals is not interrupted by osmolyte addition and dilution, respectively, and dynamic changes in fluorescence intensity were recorded for an additional $25 \mathrm{~s}$.

Cell volume measurements. Cells were dislodged with trypsin/ EDTA solution, washed, and resuspended in assay buffer (without probenecid). For each measured set of data, assay buffer with various D-mannitol concentrations was utilized to replace the system electrolyte of a Coulter Counter Z2 cell sizer (Beckman Coulter) before measuring of cell volume. Correct calibration of the system under these conditions was verified utilizing standard size latex beads (10- $\mu \mathrm{m}$ diameter; Beckman Coulter). Forty-five to sixty seconds before each measurement, cells were diluted in assay buffer containing altered D-mannitol concentrations, whereby final D-mannitol concentrations were identical to D-mannitol concentrations of the respective system electrolyte. The detection limits were set to include particles of between 300 and 3,000 fl for mean cell volume calculations.

Immunoblots and AQP2 quantification. Denaturing SDS-PAGE sample buffer [1.5\% SDS, $50 \mathrm{mM}$ Tris ( $\mathrm{pH}$ 6.8), $6 \%$ glycerol, and 15 $\mathrm{mg} / \mathrm{ml} \mathrm{DTT]} \mathrm{was} \mathrm{added} \mathrm{to} \mathrm{individual} \mathrm{wells,} \mathrm{and} \mathrm{the} \mathrm{plate} \mathrm{was} \mathrm{heated}$ at $95^{\circ} \mathrm{C}$ for $10 \mathrm{~min}$. Samples were subsequently used for immunoblotting, which was performed as previously described (6). An antibody recognizing total AQP2 (K5007) directed against the carboxylterminal tail upstream of the S256 phosphorylation site (13) was used at $1: 20,000$.

Data analysis. Linear and nonlinear fitting of data points was performed using GraphPad Prism version 5 software. To model water permeability, the "plateau followed by one phase decay" function of the software was utilized. There, experimental data points that lie before the start of a one-phase exponential decay are utilized to fit the beginning of the following, regular one-phase exponential function as well as the starting level. All fits were conducted by the least square method without constraints.

\section{RESULTS}

Initially, we were unable to record calcein fluorescence quenching in type I MDCK cells under a fluorescence microscope or on a plate reader when cells were loaded for short periods $(15 \mathrm{~min})$ or at low calcein-AM loading concentrations as described for astrocytes (28). Following longer incubation periods (60-90 min) and at higher calcein-AM concentrations $(10 \mu \mathrm{M})$, under a fluorescent microscope calcein was distributed evenly within all cells, and calcein quenching in response to D-mannitol addition became clearly visible (data not shown). Similarly, recording of calcein fluorescence quenching on a plate reader in response to D-mannitol addition was clearly visible after loading at high calcein concentrations for $90 \mathrm{~min}$, while recordings from weakly loaded cells were less reliable (data not shown). We conclude that osmotically induced volume changes from type I MDCK cells are best recorded from cells loaded at high calcein-AM concentrations $(10 \mu \mathrm{M})$ for extended periods (90 min).

To assess what degree of high intracellular fluorophore concentrations would affect the rate of shrinking of MDCK cells, we tested the response of MDCK-AQP2 cells to the addition of $150 \mathrm{mosmol} / \mathrm{kgH}_{2} \mathrm{O}$ D-mannitol. We observed significant differences between loading with 2 or $10 \mu \mathrm{M}$ calcein-AM with respect to rate ( $t$-test, $P=0.0018$, Fig. $1 A)$ or relative extent ( $t$-test, $P=0.0048$, Fig. $1 B$ ) of fluorescence change within the wells of one plate. However, the mean difference between the measured rates was small (7\% lower for high calcein concentrations), while the mean extent of relative fluorescence change was slightly larger (13\% greater for high calcein concentrations).

Cell volume changes in response to osmotic gradients can be rapid if facilitators of water permeability, such as AQPs, are present (25). Osmotic gradients can be applied to cells seeded within microwell plates through the addition of suitable buffers by a liquid-handling system. To establish the kinetics of buffer equilibration within a microwell plate, we prelaid various amounts of buffer in wells and added equal amounts of buffer containing calcein-AM using the plate reader's liquid-handling system. For mixing of $75 \mu$ plus $75 \mu l$ of calcein-AMcontaining buffer, the minimum time to equilibration was $\sim 0.5$ s (Fig. 2) above $135 \mu \mathrm{l} / \mathrm{s}$ injection speed. These values are comparable to dye exchange values shown by Solenov et al. (28) utilizing a perfusion system under a fluorescence microscope setup.

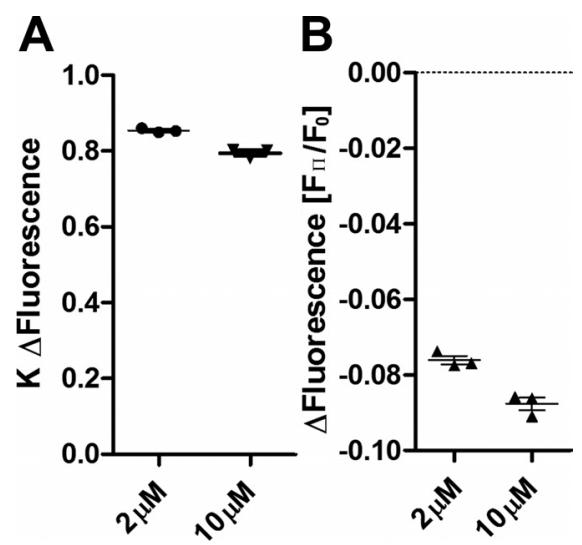

Fig. 1. Loading of type I Madin-Darby canine kidney (MDCK) cells stably transfected with aquaporin-2 (AQP2) at high $(10 \mu \mathrm{M})$ or low $(2 \mu \mathrm{M})$ calcein-AM concentration. A: little influence of calcein-AM concentration on rate constant $(K)$ of shrinking after extracellular addition of $150 \mathrm{mosmol} /$ $\mathrm{kgH}_{2} \mathrm{O}$ D-mannitol was noted. $B$ : relative fluorescence change $\left(\mathrm{F}_{\Pi} / \mathrm{F}_{0}\right.$; ratio of fluorescence $F_{\Pi}, 25 \mathrm{~s}$ after D-mannitol addition, to initial fluorescence $F_{0}$ ) following osmotic challenge was moderately higher in cells loaded with 10 $\mu \mathrm{M}$ calcein-AM. 


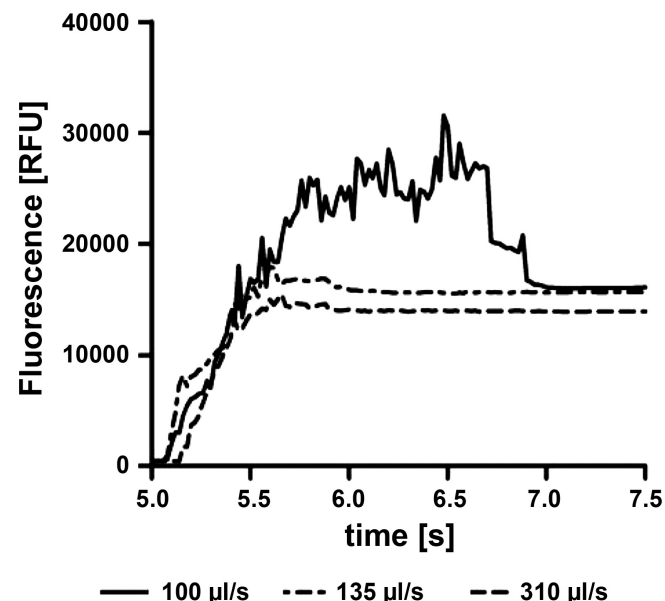

Fig. 2. To establish the time course of osmotic gradient equilibration, $75 \mu \mathrm{l}$ of isosmotic buffer were prelaid per well and $75 \mu \mathrm{l}$ of $900 \mathrm{mosmol} / \mathrm{kgH}_{2} \mathrm{O}$ buffer containing calcein were added to each well through the liquid-handling system. At injection speeds of $>135 \mu \mathrm{l} / \mathrm{s}$, equilibration was complete within $\sim 0.5 \mathrm{~s}$.

Cells that are devoid of rigid cell walls are usually considered perfect osmometers that respond to changes in extracellular osmolality with equivalent changes in cell water volume $(11,27)$. To establish empirically how fluorescence intensity is related to total cell volume, we measured fluorescence intensity of fluorophore-loaded cells and cell volume changes separately, in response to a series of osmotic gradients. First, MDCK-AQP2 cells were exposed to a series of osmotic shifts from isosmotic conditions $\left(285 \mathrm{mosmol} / \mathrm{kgH}_{2} \mathrm{O}\right)$ to final extracellular osmolalities of between 185 and $585 \mathrm{mosmol} / \mathrm{kgH}_{2} \mathrm{O}$ (Fig. 3A). The extent of fluorescence change was determined as the difference between fluorescence before and $25 \mathrm{~s}$ after alteration of extracellular D-mannitol concentrations (Fig. 3B). At this time point, fluorescence intensity appeared to be at equilibrium and we did not observe fluorescence intensity changes that could indicate regulatory volume change or cellular osmolyte (D-mannitol) permeability. The time points presented in Fig. 3 reflect recordings from within one plate (MDCK-AQP2) and were consistent between MDCK-AQP2 and separate plates of MDCK-AQP2 S256 mutants S256A and S256D, respectively (see supplementary figure for S256 mutant data and to compare data to one-phase exponential fits; all supplementary material for this article is available on the journal web site). We find a significant linear correlation of fluorescence intensity and extracellular osmolality in the whole range of osmotic shifts tested. To exclude departure from linearity at high or low extracellular osmolality, we conducted Wald-Wolfowitz runs tests. $P$ values for runs tests were 0.18 (AQP2 wild-type), 0.65 (AQP2 S256A), and 0.20 (AQP2 S256D), respectively. We conclude that fluorescence intensity in calcein-AM-loaded type I MDCK cells depends linearly on extracellular osmolality, between $\sim 185$ and $585 \mathrm{mosmol} /$ $\mathrm{kgH}_{2} \mathrm{O}$.

This correlation can be described by Eq. 1

$$
\Pi=\left[\left(\mathrm{F}_{\Pi} / \mathrm{F}_{0}\right)-b\right] / K_{\mathrm{F}}
$$

where $\mathrm{F}$ is fluorescence $\left(\mathrm{F}_{0}\right.$, before extracellular osmolality change and $\mathrm{F}_{\Pi}, 25 \mathrm{~s}$ after extracellular osmolality change), $b$ and $K_{\mathrm{F}}$ are the $y$-intersect and the slope of the linear regression line, respectively, and $\Pi$ represents extracellular osmolality.
Values utilized for water permeability calculations were from measurements depicted in Fig. $3 B$.

To evaluate the discriminatory power of the assay we calculated the SD of each fluorescence intensity change in the experiment shown in Fig. 3 and replicate plates and compared these SDs with the average fluorescence intensity changes with $25 \mathrm{mosmol} / \mathrm{kgH}_{2} \mathrm{O}$ gradient steps. We found that between three and seven replicate wells were necessary to distinguish 25 mosmol $/ \mathrm{kgH}_{2} \mathrm{O}$ osmotic shifts within one plate with a probability of $95 \%$ and a power of $90 \%$.

Cell volume changes in type I MDCK cells in response to changes in extracellular osmolality were recorded from suspended cells using a Coulter counter. This instrument is capable of recording average cell volumes between electrodes as proportional to electrical impedance changes from a large number of cells $(10,000$ cells/run were measured). The methodology has been evaluated for MDCK cells previously. Good correlation between cell water volume of mildly trypsinized cells in suspension determined in a Coulter counter and cell water volume of adherent MDCK cells determined by 3-omethyl glucose uptake has been described (27). Furthermore, a comparable strategy has been employed to record cell water permeability in human spermatozoa (11) and malignant astrocytes (18). Similarly to the fluorescence intensity measurements (Fig. 3), cell volume measurements were recorded $45 \mathrm{~s}$ after a shift of extracellular osmolality from isosmotic ( 285 mosmol $/ \mathrm{kgH}_{2} \mathrm{O}$ ) to a range of other osmolalities (Fig. 4).

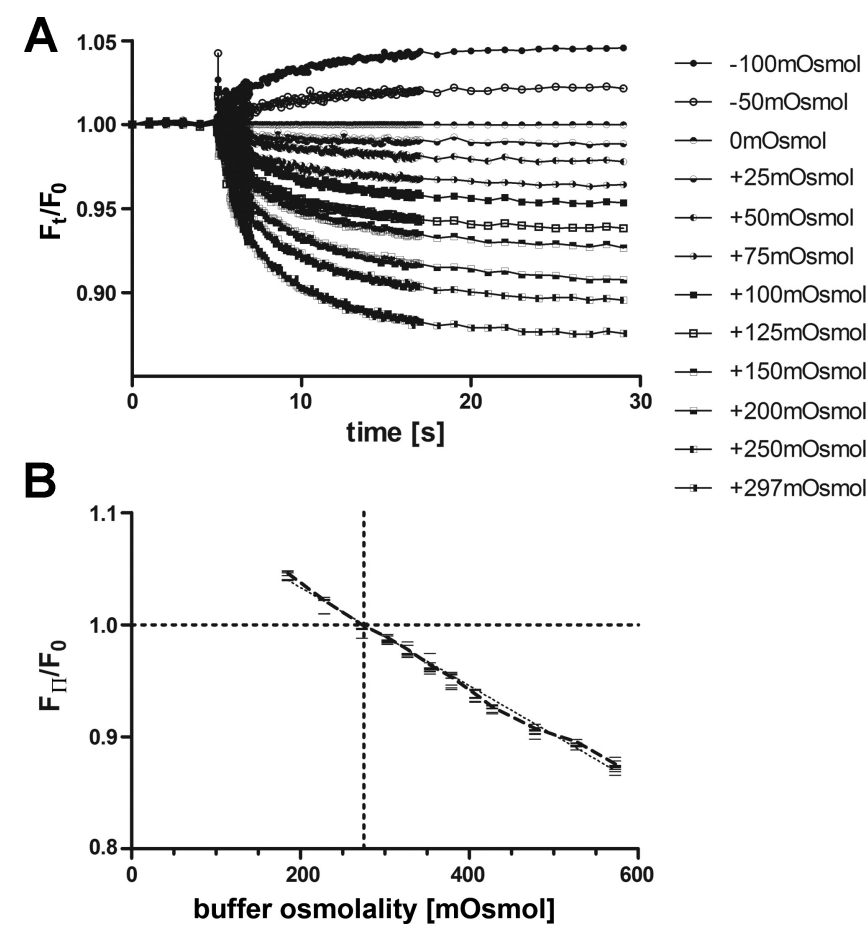

Fig. 3. A series of osmotic shifts starting at isosmotic $\left(285 \mathrm{mosmol} / \mathrm{kgH}_{2} \mathrm{O}\right)$ and ending at between $185\left(-100 \mathrm{mosmol} / \mathrm{kgH}_{2} \mathrm{O}\right)$ and $582 \mathrm{mosmol} / \mathrm{kgH}_{2} \mathrm{O}$ $\left(+297 \mathrm{mosmol} / \mathrm{kgH}_{2} \mathrm{O}\right)$ final extracellular osmolality was conducted to establish the relationship between relative intracellular fluorescence and extracellular osmolality. Average fluorescence intensity (described as the ratio $\mathrm{F}_{t} / \mathrm{F}_{0}$ of fluorescence $\mathrm{F}$ at time $t$ to initial fluorescence $\mathrm{F}_{0}$ ) in 8 replicate wells before and after application of indicated osmotic shifts over time is depicted $(A)$ and plotted as $\mathrm{F}_{\Pi} / \mathrm{F}_{0}$ (ratio of fluorescence $\mathrm{F}_{\Pi}, 25 \mathrm{~s}$ after D-mannitol addition, to initial fluorescence $\left.\mathrm{F}_{0} ; B\right)$. Both linear regression (dotted line) and a connecting line of averages (dashed line) are indicated. 


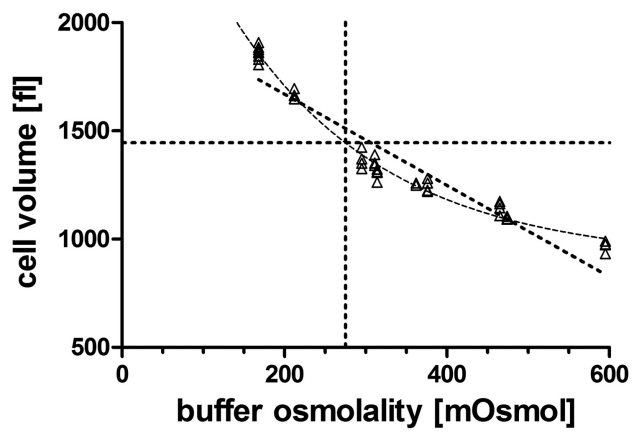

Fig. 4. Measurements of type I MDCK cell volume in a Z2 Coulter counter. Cells were dislodged by gentle trypsin/EDTA treatment and resuspended in isosmotic assay buffer. Approximately $45 \mathrm{~s}$ before measurements, assay buffer was diluted with buffers of altered osmotic values. Cell volume responses to altered extracellular osmolality closely follow an exponential curve. Linear regression analysis of the data set is also indicated. Each triangle reflects the mean cell volume of 10,000 cells in an individual measurement.

Linear regression analysis of the obtained data set resulted in a lower $r^{2}$ score (0.89) compared with least square fitting to an exponential function $\left(r^{2}=0.99\right)$. We concluded that the effect of extracellular osmolality on cell volume is best described by $E q$. 2, where an exponential equation in its general form was solved for $\Pi$

$$
\Pi=\left\{\ln \left[\left(\mathrm{V}_{\Pi}-V_{\min }\right) /\left(V_{\max }-V_{\min }\right)\right]\right\} /-K_{\mathrm{v}}
$$

where $\mathrm{V}_{\Pi}$ is volume at $\Pi, V_{\max }$ and $V_{\min }$ are the theoretical limits of the exponential function deduced by least square fitting of the data in Fig. 4, $K_{\mathrm{V}}$ is the corresponding rate constant, and $\Pi$ is extracellular osmolality.

Based on these observations, cell volume cannot be deduced directly from calcein-AM fluorescence intensity. Rather, measurements of cell volume and fluorescence intensity in relation to extracellular osmolality have to be combined to calculate cell volume from fluorescence intensity values. Solving Eqs. 1 and 2 for cell volume, we deduced Eq. 3

$$
\mathrm{V}_{\Pi}=V_{\min }+\left[V_{\max }-V_{\min }\right] \cdot e^{-K_{\mathrm{v}} \cdot\left[\left(\mathrm{F}_{\Pi} / \mathrm{F}_{0}\right)-b\right] / K_{\mathrm{F}}}
$$

Values obtained from measurements depicted in Fig. 3 and 4 were $K_{\mathrm{F}}=-0.0004384, b=1.121, V_{\max }=3,216 \mathrm{fl}, V_{\min }=$ $901.7 \mathrm{fl}, K_{\mathrm{V}}=0.005267$. Assuming that fluorescence change after reaching equilibrium between extracellular and intracellular osmolality $\left(\mathrm{F}_{\Pi} / \mathrm{F}_{0}\right)$ closely mimics fluorescence intensity during dynamic fluorescence changes $\left(\mathrm{F}_{t} / \mathrm{F}_{0}\right)$, fluorescence intensity values recorded on a plate reader over time, in response to an osmotic shift, can now be translated into volume changes over time. Fitting the resulting values to a standard exponential decay function (equation 4) allows us to calculate the rate as well as the rate constant of volume change at any point in time following an extracellular osmolality change using Eq. 4

$$
\mathrm{V}_{\mathrm{n}}=V_{\min 2}+\left[\mathrm{V}_{0}-V_{\min 2}\right] \cdot e^{-K \cdot\left(t_{\mathrm{n}}-t_{0}\right)}
$$

where $\mathrm{V}_{\mathrm{n}}$ is the cell volume at time $t=\mathrm{n}, \mathrm{V}_{0}$ is the cell volume before D-mannitol addition, and $V_{\min 2}$ is the lower limit of cell shrinkage for each measurement. Thus $\mathrm{V}_{0}-V_{\min 2}$ reflects the total volume change in response to the extracellular osmolality change. $K$ is the rate constant of the exponential decay in $x$-axis units. It follows that $K \cdot\left[\mathrm{V}_{0}-V_{\min 2}\right]$ describes the theoretical fraction of total volume change per one $x$-axis unit change (i.e., $1 \mathrm{~s}$ ) at the initial rate of volume change (usually referred to as
$J_{\mathrm{v}}$, the volume flow across the semipermeable membrane). We conclude that cell water permeability coefficient $P_{\mathrm{f}}$ of calceinAM-loaded MDCK cells from fluorescence intensity recordings can be calculated according to Eq. 5

$$
P_{\mathrm{f}}=\left\{K \cdot\left[\mathrm{V}_{0}-V_{\min 2}\right]\right\} /\left[A \cdot \Delta \Pi \cdot \mathrm{V}_{\mathrm{w}}\right]
$$

where $A$ describes cell surface area and, $\mathrm{V}_{\mathrm{w}}$ is the partial molar volume of water $\left(1.8 \times 10^{-5} \mathrm{~m}^{3} / \mathrm{mol}\right)$, and $\Delta \Pi$ describes the applied osmotic gradient.

In our plate reader setup, application of the osmotic gradient was exclusively from above and consequently all cell water exchange occurs at the apical plasma membrane, making our set-up suitable for measuring apical membrane water permeability. However, estimates of apical surface area are required to calculate $P_{\mathrm{f}}$. Since MDCK cells are known to form membrane protrusions that enhance the apical surface, we considered it unsuitable to obtain estimates for the water-conductive area by light/confocal microscopic methods. Hence we utilized published values for the type I MDCK cell apical surface (1) to calculate the following cell water permeability coefficients for type I MDCK cells transfected with wild-type AQP2 or two different, well-characterized mutant isoforms of AQP2 that affect membrane trafficking of this protein: 1) AQP2-S256D, $\left.P_{\mathrm{f}}=2.5 \pm 0.6 \mathrm{SD} \times 10^{-4} \mathrm{~m} / \mathrm{s} ; 2\right) \mathrm{AQP} 2$ wild-type, $P_{\mathrm{f}}=$ $1.1 \pm 0.4 \times 10^{-4} \mathrm{~m} / \mathrm{s}$; and 3$) \mathrm{AQP} 2-\mathrm{S} 256 \mathrm{~A}, P_{\mathrm{f}}=5.5 \pm 0.5$ $\mathrm{SD} \times 10^{-5} \mathrm{~m} / \mathrm{s}$. By comparison, untransfected type I MDCK cells displayed a cell water permeability of $P_{\mathrm{f}}=6.1 \pm 2.5$ $\mathrm{SD} \times 10^{-5} \mathrm{~m} / \mathrm{s}$. As AQP2 abundances were slightly different between cell lines, and to facilitate comparison between experiments, unit cell water permeability coefficients were calculated, with average cell water permeability normalized to the AQP2 expression level (Fig. 5). Thereby, AQP-2 expression levels were quantified from densitometry of immunoblots (data not shown).

\section{DISCUSSION}

The goal of the present study was to develop an efficient method for measuring cell water permeability in a polarized kidney cell line. The cell-impermeable calcein fluorophore can be loaded into mammalian cells in high concentrations by passive diffusion of the membrane-permeable AM ester derivative across the membrane and subsequent cleavage of the AM moiety by intracellular esterases. Calcein is distributed evenly throughout cells and is not sensitive to physiological changes in calcium, $\mathrm{pH}$, or $\mathrm{NaCl}$ concentrations $(28,36)$. Cell volumedependent fluorophore intensity changes have been previously shown to be rapid (28). It is thus reasonable to expect that dynamic changes in fluorescence intensity do not trail significantly behind actual changes in cell volume following an osmotic challenge. Consequently, this behavior of calcein has been exploited previously to study AQP function under a fluorescent microscope $(12,28)$. Furthermore, in both studies, equations for extracting putative cell water volume changes directly from fluorescence intensity changes have been described $(12,28)$. When larger sets of experimental conditions need to be compared, these methods can become inconvenient. We reasoned that it should be possible to utilize the fluorescent properties of calcein-AM for measuring cell volume changes on a standard plate reader. The plate reader employed in the present study is a simple model which is suitable for rapid 


\section{F228 PLATE READER-BASED WATER PERMEABILITY MEASUREMENTS}
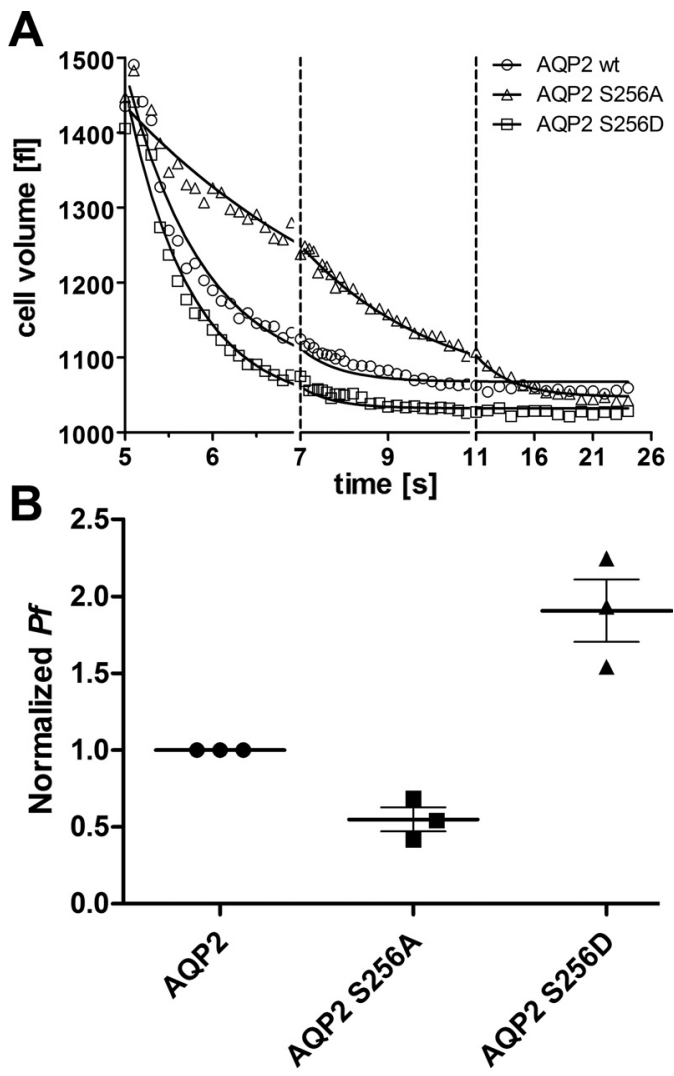

Fig. 5. Cell water permeability in type I MDCK cells stably transfected with 3 different AQP2 isoform-encoding constructs. Sample traces for cell shrinking follow shift of extracellular osmolarity at $5 \mathrm{~s}$ into the recording from 285 to $585 \mathrm{mosmol} / \mathrm{kgH}_{2} \mathrm{O}$ by addition of D-mannitol. All cell volume data points were calculated from fluorescence intensity values as indicated in the text; data were fit to a one-phase exponential function. Data points recorded before application of the osmotic gradient were excluded from the fit; $r^{2}$ values of fit are in brackets: $\bigcirc$, AQP2 wild-type (0.97); $\triangle$, AQP2 S256A (0.99); $\square$, AQP2 S256D $(0.98 ; A) . B$ : highest water permeability $\left(P_{\mathrm{f}}\right)$ was observed in cells expressing a S256D mutant isoform of AQP2 that is known for its enhanced apical localization. Intermediate water permeability was observed in cells expressing wild-type AQP2, while cells expressing the S256A isoform of AQP2 showed lowest water permeability. Average $P_{\mathrm{f}}$ values from 3 replicate wells were normalized to AQP2 protein abundance. Three independent experiments were conducted, and each plotted data point represents 1 independent experimental value. Horizontal lines indicate means and SE (B).

detection of fluorescence changes and includes a liquid-handling system that can be used to change extracellular osmolality during fluorescence recordings. It is expected that the presented method is not limited to the equipment utilized here and could be adapted for any system capable of measuring fluorescence at 485-nm excitation/515-nm emission.

Mammalian cells are typically regarded as perfect osmometers, whereby a fraction of the cytosol appears to be osmotically inactive (11). Traditionally, this osmotically inactive portion has been estimated, following direct vs. reciprocal plotting of cell volume vs. extracellular osmolality measurements (11). In a similar approach, we have determined the relationship between both fluorescence intensity and cell volume, respectively, and extracellular osmolality; but through direct experimental measurements. In calcein-AM-loaded cells, we observed a linear dependence of fluorescence intensity on extracellular buffer osmolality, after equilibrium between intracellular and extracellular osmolarity had been reached. In contrast, cell volume dependence on buffer osmolality at equilibrium was hardly linear but closely followed an exponential function. We interpret this observation as a gradual increase in mechanical back-pressure derived from reduction of nonsoluble intracellular compartments, such as organelles and cytoskeleton, when the cells shrink. Consequently, we propose that cell volume changes following an extracellular osmotic shift cannot be calculated directly from calcein fluorescence intensity changes, as suggested previously (12). Rather, both cell volume and fluorescence intensity have to be determined over the range of an extracellular osmolality calibration curve, to determine cell volume from relative fluorescence intensity. One potential caveat in this analysis, which has to be regarded as a model, is that fluorescence values were measured at equilibria of extracellular osmolality to obtain a standard curve, which was then applied to calculate a dynamically changing cell volume.

As in other methods of measuring membrane water permeability, an osmotic gradient is applied to a semipermeable membrane-enclosed compartment and the resulting volume flow across the membrane is measured. Ideally, this requires that the extracellular osmolality shift is applied instantaneously, which is only theoretically possible. Extracellular osmolality changes could be established within $0.5 \mathrm{~s}$ in our plate reader-based system, which is comparable to microscopebased methods of cell water permeability measurements (28). However, when water permeability in cells is very high, this buffer-mixing time, rather than transmembrane water flux, may become limiting for measuring shrinking or swelling rates. Based on dye dilution time courses, we estimate that maximum water permeabilities of $\sim 1 \times 10^{-3} \mathrm{~m} / \mathrm{s}$ can be observed in type I MDCK cells.

Limitations of the technique. The value of calculating water permeability coefficients is considered to lie in the comparability of cell water permeabilities between experimental systems (35). This requires, however, that reasonable estimates of the actual water-permeable surface of a cell can be obtained, which can differ significantly through numerous factors. For example, the exact culture conditions, e.g., cell confluency or fixation conditions, may affect the apparent apical membrane surface. Additionally, like many epithelial cells, type I MDCK cells change morphology when they form confluent monolayers, with numerous apical protrusions or microvilli. Examination of cells using light/confocal microscopy will likely overlook these fine protrusions, which can enhance surface area significantly. We thus calculated $P_{\mathrm{f}}$ values based on published values for type I MDCK cell apical cell surface that were measured on transmission electron microscopy-captured images. It has to be considered, however, that these measurements were obtained from cells seeded on polycarbonate filters (0.2- $\mu \mathrm{m}$ pore size), before fixation and ultrathin sectioning. Butor and Davoust (1) found significant differences in morphology between type II MDCK cells seeded on various filter supports. We note that cell volume measurements were comparable between the two studies, 1,495 fl (1) vs. 1,417 fl (this study), under isosmotic conditions. However, caution must be taken in interpreting these data, as it can be expected that the morphology between unfixed type I MDCK cells seeded on plastic in multiwell plates and fixed cells on polycarbonate filters is not the same. When comparing the values for cell water permeability obtained in this study to earlier published values of MDCK transmembrane permeability, we note a relatively large range for $P_{\mathrm{f}}$, from $1.8 \times 10^{-6} \mathrm{~m} / \mathrm{s}$ to $2.4 \times$ 
$10^{-5} \mathrm{~m} / \mathrm{s}$, depending on the experimental system and most likely also on precise cell culture conditions $(3,5,16,26,31)$. In light of these results, our values for $P_{\mathrm{f}}$ appear somewhat high $\left(6 \times 10^{-5} \mathrm{~m} / \mathrm{s}\right)$ but agree well with other values suggested for water permeability through a lipid bilayer $(28,35)$. We note that some variability of $P_{\mathrm{f}}$ in our system is introduced by an imperfect fit of swelling/shrinking data to a one-phase exponential function (compare Fig. 5A), and thus measurements of the rate constant $K$ become slightly uncertain. We found better $r^{2}$ (typically $>0.9$ ) values for fits where larger osmotic gradients $\left(>200 \mathrm{mosmol} / \mathrm{kgH}_{2} \mathrm{O}\right)$ were applied and concluded that $P_{\mathrm{f}}$ is best measured at gradients of $200-300 \mathrm{mosmol} / \mathrm{kgH}_{2} \mathrm{O}$ in our system. As suggested previously by van Heeswijk and van Os (33), proper swelling/shrinking data fit to a one-phase exponential function requires that a uniform population of membrane-enclosed compartments be measured. All cell lines utilized in this study where immunolabeled using anti AQP2 antiserum before water permeability measurements, and we found that in all cell lines $>95 \%$ of cells expressed AQP2 (data not shown). We thus considered fitting to a one-phase exponential function appropriate but conclude that caution against direct comparison of $P_{\mathrm{f}}$ values between this and alternative experimental platforms must be exercised. Finally, before any type of comparison between experimental platforms, differences in expression levels of the protein of interest, e.g., water channels between heterologous expression systems and native tissues, must be considered.

Application to kidney physiology. MDCK cells have frequently been used to study proteins involved in kidney physiology, e.g., AQP water channels and urea transporters $(9,22$, 24). Under resting conditions, AQP2, is located in subapical membrane vesicles in principal cells of the collecting duct. Binding of the pituitary hormone arginine vasopressin (AVP) to the type II vasopressin receptor results in phosphorylation of AQP2 at several sites near its carboxyl terminus and AQP2 apical membrane insertion. Protein kinase A phosphorylation of S256 in AQP2 has been shown to be essential for this accumulation on the membrane $(10,14 a, 15,17)$. Consequently, AQP2-S256A mutant protein, which mimics a dephosphorylated state, has been found to localize primarily in intracellular vesicles $(14,32)$. In contrast, enhanced plasma membrane localization was found for AQP2-S256D mutants, which mimic a phosphorylated state of AQP2. To test the described experimental setup practically, we have utilized MDCK cells stably transfected with these three different forms of AQP2. In agreement with previous studies on the localization of the three isoforms, we found the highest water permeability in cells transfected with AQP2-S256D, and low water permeability close to transmembrane water permeability in untransfected type I MDCK cells, in AQP2-S256A-transfected cells.

In a recent study, Møller et al. (20) have demonstrated the influence of several synthetic point mutations near the carboxyl terminus of AQP2 on cell water permeability in X. laevis oocytes. There, except for the S256A form of AQP2, no significant differences were found in oocyte water permeability. The authors pointed out that phosphorylation-regulated localization and function of AQP2 in X. laevis oocytes may be different from the protein's fate in its native tissue for three reasons: 1) necessary chaperones may not be present in these amphibian cells; 2) the influence of conformational changes as a result of altered phosphorylation may be different in amphibian cells that have to be incubated at typically $16-18^{\circ} \mathrm{C}$ for heterologous protein expression, in contrast to $37^{\circ} \mathrm{C}$ in typical mammalian tissues; and 3) interacting proteins responsible for retrieval of AQP2 from the plasma membrane may be absent. Our results obtained with AQP2-S256 mutant-expressing MDCK cells suggest that the presented method is well suited to address these issues.

We finally suggest that the presented method is not limited to MDCK cells since we have successfully established protocols for measuring water permeability in other adherent cell lines, i.e., Chinese hamster ovary cells and U87MG (human astrocytoma) cells (Rützler M, unpublished observations).

Furthermore it should be feasible to utilize the described method to screen chemical compound libraries for AQP inhibitors, since the degree of throughput is only limited by the plate reader's technical specifications and available pipetting capacities. There is considerable interest in identifying lead compounds that would enhance development of diuretic drugs that facilitate excretion of water without concurrent salt loss (34), to treat cytotoxic brain edema $(23,29)$, and to prevent tumor vascularization (30). We note that during the submission process of this manuscript, a study was published that describes the use of a similar technical setup in the identification of AQP inhibitors in a chemical compound library (21).

\section{ACKNOWLEDGMENTS}

Expert technical assistance was provided by Christian V. Westberg and Anne Gylling. Charlotte Rohde Knudsen is acknowledged for permitting the use of a Coulter counter device. We thank Dr. Mark Knepper for providing antibody K5007.

\section{GRANTS}

This work was supported by the Lundbeck Foundation and a Nordic Centre of Excellence in Water-Imbalance Related Disorders Grant. Further funding was provided by the Danish Medical Research Council (to R. A. Fenton), the Novo Nordisk Foundation (to R. A. Fenton), the Carlsberg Foundation (to R. A. Fenton), and a Marie Curie Intra-European Fellowship (to R. A. Fenton). The Water and Salt Research Center at the University of Aarhus is established and supported by the Danish National Research Foundation (Danmarks Grundforskningsfond).

\section{DISCLOSURES}

No conflicts of interest are declared by the authors.

\section{REFERENCES}

1. Butor C, Davoust J. Apical to basolateral surface area ratio and polarity of MDCK cells grown on different supports. Exp Cell Res 203: 115-127, 1992

2. Chen RF, Knutson JR. Mechanism of fluorescence concentration quenching of carboxyfluorescein in liposomes: energy transfer to nonfluorescent dimers. Anal Biochem 172: 61-77, 1988

3. Farinas J, Kneen M, Moore M, Verkman AS. Plasma membrane water permeability of cultured cells and epithelia measured by light microscopy with spatial filtering. J Gen Physiol 110: 283-296, 1997.

4. Farinas J, Simanek V, Verkman AS. Cell volume measured by total internal reflection microfluorimetry: application to water and solute transport in cells transfected with water channel homologs. Biophys $J$ 68: 1613-1620, 1995.

5. Farinas J, Verkman AS. Cell volume and plasma membrane osmotic water permeability in epithelial cell layers measured by interferometry. Biophys J 71: 3511-3522, 1996.

6. Fenton RA, Brond L, Nielsen S, Praetorius J. Cellular and subcellular distribution of the type-2 vasopressin receptor in the kidney. Am J Physiol Renal Physiol 293: F748-F760, 2007. 
7. Fenton RA, Knepper MA. Mouse models and the urinary concentrating mechanism in the new millennium. Physiol Rev 87: 1083-1112, 2007.

8. Fenton RA, Knepper MA. Urea and renal function in the 21st century: insights from knockout mice. J Am Soc Nephrol 18: 679-688, 2007.

9. Frohlich O, Klein JD, Smith PM, Sands JM, Gunn RB. Regulation of UT-A1-mediated transepithelial urea flux in MDCK cells. Am J Physiol Cell Physiol 291: C600-C606, 2006.

10. Fushimi K, Sasaki S, Marumo F. Phosphorylation of serine 256 is required for cAMP-dependent regulatory exocytosis of the aquaporin-2 water channel. J Biol Chem 272: 14800-14804, 1997.

11. Gilmore JA, McGann LE, Liu J, Gao DY, Peter AT, Kleinhans FW, Critser JK. Effect of cryoprotectant solutes on water permeability of human spermatozoa. Biol Reprod 53: 985-995, 1995.

12. Hamann S, Kiilgaard JF, Litman T, Alvarez-Leefmans FJ, Winther BR, Zeuthen T. Measurement of cell-volume changes by fluorescence self-quenching. J Fluor 12: 139-145, 2002.

13. Hoffert JD, Fenton RA, Moeller HB, Simons B, Tchapyjnikov D, McDill BW, Yu MJ, Pisitkun T, Chen F, Knepper MA. Vasopressinstimulated increase in phosphorylation at Ser269 potentiates plasma membrane retention of aquaporin-2. J Biol Chem 283: 24617-24627, 2008.

14. Katsura T, Gustafson CE, Ausiello DA, Brown D. Protein kinase A phosphorylation is involved in regulated exocytosis of aquaporin-2 in transfected LLC-PK 1 cells. Am J Physiol Renal Physiol 272: F817-F822, 1997.

14a.Klokkers J, Langehanenberg P, Kemper B, Kosmeier S, von Bally G, Riethmuller C, Wunder F, Sindic A, Pavenstadt H, Schlatter E, and Edemir B. Atrial natriuretic peptide and nitric oxide signaling antagonizes vasopressin-mediated water permeability in inner medullary collecting duct cell. Am J Physiol Renal Physiol 297: F693-F703, 2009.

15. Kuwahara M, Fushimi K, Terada Y, Bai L, Marumo F, Sasaki S. cAMP-dependent phosphorylation stimulates water permeability of aquaporin-collecting duct water channel protein expressed in Xenopus oocytes. J Biol Chem 270: 10384-10387, 1995.

16. Lavelle JP, Negrete HO, Poland PA, Kinlough CL, Meyers SD, Hughey RP, Zeidel ML. Low permeabilities of MDCK cell monolayers: a model barrier epithelium. Am J Physiol Renal Physiol 273: F67-F75, 1997.

17. Lu HJ, Matsuzaki T, Bouley R, Hasler U, Qin QH, Brown D. The phosphorylation state of serine 256 is dominant over that of serine 261 in the regulation of AQP2 trafficking in renal epithelial cells. Am J Physiol Renal Physiol 295: F290-F294, 2008.

18. McCoy E, Sontheimer H. Expression and function of water channels (aquaporins) in migrating malignant astrocytes. Glia 55: 1034-1043, 2007.

19. Meinild AK, Klaerke DA, Zeuthen T. Bidirectional water fluxes and specificity for small hydrophilic molecules in aquaporins 0-5. J Biol Chem 273: 32446-32451, 1998.

20. Moeller HB, MacAulay N, Knepper MA, Fenton RA. Role of multiple phosphorylation sites in the $\mathrm{COOH}$-terminal tail of aquaporin-2 for water transport: evidence against channel gating. Am J Physiol Renal Physiol 296: F649-F657, 2009.

21. Mola MG, Nicchia GP, Svelto M, Spray DC, Frigeri A. Automated cell-based assay for screening of aquaporin inhibitors. Anal Chem 81: 8219-8229, 2009.

22. Nejsum LN, Zelenina M, Aperia A, Frøkiær J, Nielsen S. Bidirectional regulation of AQP2 trafficking and recycling: involvement of AQP2-S256 phosphorylation. Am J Physiol Renal Physiol 288: F930-F938, 2005.

23. Papadopoulos MC, Krishna S, Verkman AS. Aquaporin water channels and brain edema. Mt Sinai J Med 69: 242-248, 2002.

24. Potter EA, Stewart G, Smith CP. Urea flux across MDCK-mUT-A2 monolayers is acutely sensitive to AVP, cAMP, and $\left[\mathrm{Ca}^{2+}\right]_{\mathrm{i}}$. Am J Physiol Renal Physiol 291: F122-F128, 2006.

25. Preston GM, Carroll TP, Guggino WB, Agre P. Appearance of water channels in Xenopus oocytes expressing red cell CHIP28 protein. Science 256: 385-387, 1992

26. Rivers RL, McAteer JA, Clendenon JL, Connors BA, Evan AP, Williams JC Jr. Apical membrane permeability of MDCK cells. Am J Physiol Cell Physiol 271: C226-C234, 1996.

27. Simmons NL. Epithelial cell volume regulation in hypotonic fluids: studies using a model tissue culture renal epithelial cell system. $Q J$ Exp Physiol 69: 83-95, 1984.

28. Solenov E, Watanabe H, Manley GT, Verkman AS. Sevenfold-reduced osmotic water permeability in primary astrocyte cultures from AQP-4deficient mice, measured by a fluorescence quenching method. Am J Physiol Cell Physiol 286: C426-C432, 2004.

29. Saadoun S, Papadopoulos MC. Aquaporin-4 in brain and spinal cord oedema. Neuroscience. In press.

30. Saadoun S, Papadopoulos MC, Hara-Chikuma M, Verkman AS. Impairment of angiogenesis and cell migration by targeted aquaporin-1 gene disruption. Nature 434: 786-792, 2005.

31. Timbs MM, Spring KR. Hydraulic properties of MDCK cell epithelium. J Membr Biol 153: 1-11, 1996.

32. van Balkom BW, Savelkoul PJ, Markovich D, Hofman E, Nielsen S, van der Sluijs P, Deen PM. The role of putative phosphorylation sites in the targeting and shuttling of the aquaporin-2 water channel. J Biol Chem 277: 41473-41479, 2002.

33. van Heeswijk MP, van Os CH. Osmotic water permeabilities of brush border and basolateral membrane vesicles from rat renal cortex and small intestine. J Membr Biol 92: 183-193, 1986.

34. Verkman AS. Roles of aquaporins in kidney revealed by transgenic mice. Semin Nephrol 26: 200-208, 2006.

35. Verkman AS. Water permeability measurement in living cells and complex tissues. J Membr Biol 173: 73-87, 2000.

36. Wehner F, Sauer H, Kinne RK. Hypertonic stress increases the $\mathrm{Na}+$ conductance of rat hepatocytes in primary culture. J Gen Physiol 105: 507-535, 1995.

37. Zeidel ML, Ambudkar SV, Smith BL, Agre P. Reconstitution of functional water channels in liposomes containing purified red cell CHIP28 protein. Biochemistry 31: 7436-7440, 1992. 